\title{
The Top Ten Similarities between Playing Hockey and Building a Better Internet
}

\author{
Martin Arlitt \\ HP Labs, Palo Alto, CA and University of Calgary, Calgary, AB \\ martin.arlitt@hp.com
}

This article is an editorial note submitted to CCR. It has NOT been peer reviewed. The author takes full responsibility for this article's technical content. Comments can be posted through CCR online.

\begin{abstract}
Time tends to pass more quickly than we would like. Sometimes it is helpful to reflect on what you have accomplished, and to derive what you have learned from the experiences. These "lessons learned" may then be leveraged by yourself or others in the future. Occasionally, an external event will motivate this self reflection. For me, it was the 50th anniversary reunion of the St. Walburg Eagles, held in July 2011. The Eagles are a full-contact (ice) hockey team I played with between 1988 and $1996^{1}$, while attending university. What would I tell my friends and former teammates that I had been doing for the past $15+$ years? After some thought, I realized that my time as an Eagle had prepared me for a research career, in ways I would never have imagined. This article $^{2}$ shares some of these similarities, to motivate others to reflect on their own careers and achievements, and perhaps make proactive changes as a result.
\end{abstract}

\section{Categories and Subject Descriptors}

K.7.0 [Computing Milieux]: The Computing ProfessionGeneral

\section{General Terms}

Human Factors, Performance, Measurement, Algorithms

\section{Keywords}

hockey, Internet, St. Walburg Eagles, similarities, fun

\section{Introduction}

When I first started working for HP Labs (in 1997), my friends and family in rural Saskatchewan would all ask me what I was working on. If I told them I was characterizing the workloads of Web servers or evaluating the performance of Web proxies, the typical reaction was a puzzled look. So when I went home for Christmas that first year, I decided to describe my work in a slightly different manner. When my uncle Bob (a carpenter who takes great pride in building things quickly and correctly) asked me what I was working on, I said I was trying to make the Internet go faster. He said that was good, because his "Internet" was really slow.

\footnotetext{
${ }^{1}$ The Eagles ceased operations twice during this period, which limited me to four seasons playing with them.

${ }^{2} \mathrm{An}$ extended version with color photos is available in [1].
}

The following Christmas I saw my Uncle Bob again. One of his comments was "Well Martin, the Internet still sucks!", meaning that I still had a lot of work to do.

In a nutshell, "building a better Internet" summarizes the motivation behind much of the work in the entire SIGCOMM community for the past several decades. My intent with this editorial is twofold: to share my "lessons learned" with the community, particularly with new members seeking to establish themselves; and to motivate other seasoned veterans to share their experiences.

\section{How the Internet is like hockey}

Since (ice) hockey is not the most popular sport in the world, I'll provide a brief overview. I'll also point out some similarities between the Internet and the game of hockey.

The Internet involves a lot of infrastructure: data centers to house servers, client devices to interact with the servers, and fiber optic and wireless networks to connect them. Hockey also requires a significant amount of infrastructure. Hockey is played on a rectangular sheet of ice, typically inside a building called an arena or a rink. In North America, the ice is 200' long by 85 ' wide; in most of the rest of the world, it is $15^{\prime}$ wider. Figure 1 shows the layout of the playing area of an arena.

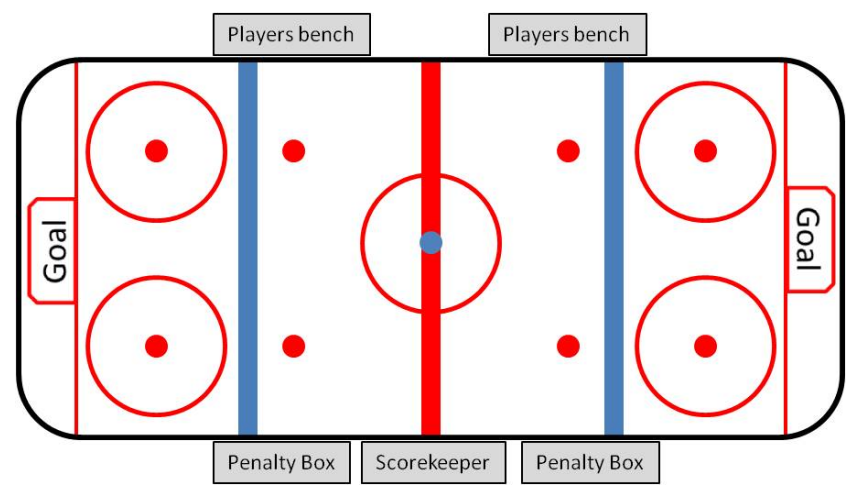

Figure 1: Layout of an ice hockey playing area.

A game involves two teams, each defending a goal at opposite ends of the ice. For the team defending the goal on the right-hand side of Figure 1, the right-most third of the ice (from the rightmost blue line to the right-side of the figure) is called their "defending zone". The area between the 
two blue lines is the "neutral zone". The remaining third of the ice (from the leftmost blue line to the left end of the ice) is their "attacking zone". Each team plays with 5 players (left wing, center, right wing, left defense, right defense) and 1 goaltender (goalie for short) on the ice at a time. The remaining players on the team sit on the team's "players bench". The objective in hockey is to put a small rubber disk called a "puck" into the goal in the attacking zone more times than your opponent puts the puck into your goal. For a "goal" to count, it must be shot into the goal with a "stick"; it cannot be thrown or kicked in.

The game of hockey has a number of similarities to how the Internet operates. First, there are flow control mechanisms that attempt to maintain a desired pace. "Icing" occurs when a defending team shoots the puck from their half of the ice (the middle is denoted by the center red line) all the way past the goal line in the attacking zone. "Offsides" occurs if a player enters their attacking zone before the puck crosses the blue line between the neutral zone and the attacking zone. (In contrast to football/soccer, the positioning of the defending players does not matter.) Two onice officials called linesmen are responsible for implementing these flow control mechanisms.

Second, there are "rules of engagement" that attempt to deter undesirable activities. As with the Internet, some participants will "bend" the rules to try and gain an advantage for themselves. Like a network protocol specification, there are a lot of possibilities to cover. Although too numerous to mention here, the rules of hockey can generally be categorized as mechanisms to deter "impeding the movement of an opponent", "excessive physical aggression against an opponent", "excessive use of a stick against an opponent", and "other undesirable behavior". A "referee" is an on-ice official responsible for enforcing these rules. If a team is assessed a penalty, they go on the "penalty kill" and play "short-handed" for the duration of the penalty, while the other team goes on the "power play".

\section{The top ten similarities}

There are a lot of similarities between playing hockey and conducting research to build a better Internet. I chose to limit the comparison to the following ten.

\section{Team Work}

Playing hockey and building a better Internet both require teams of skilled individuals. Some members are specialists at certain roles, while others are good at almost everything. There are leaders and followers, rookies and veterans. Everyone contributes to a shared objective in their own way. Figure 2 and Figure 3 show two of the best teams I've ever been on. Both have members possessing the characteristics that I just described. The only real difference is the hair styles. While somewhat difficult to see in Figure 2, the "mullet" (short on top and sides, long in the back) was the common choice on the Eagles, but is extremely rare at HP.

\section{Climate controlled environments}

As previously mentioned, hockey is played in an arena or rink. Figure 4 shows the St. Walburg arena where the Eagles play their home games. When I was a child, most of the rinks I played on used "natural" ice. That is, they relied on the long, cold Canadian winters to keep ice in the

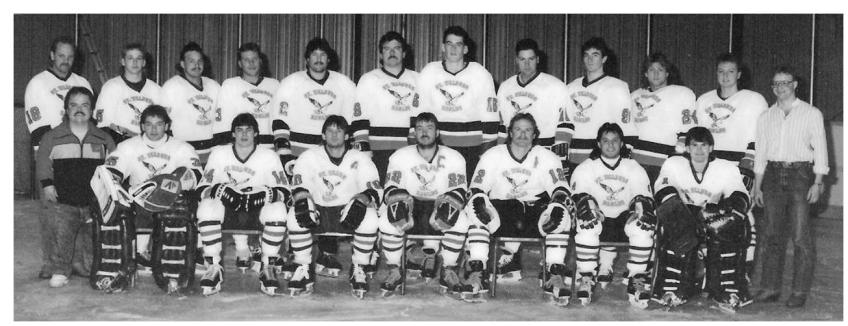

Figure 2: St. Walburg Eagles, 1990-1991 season.

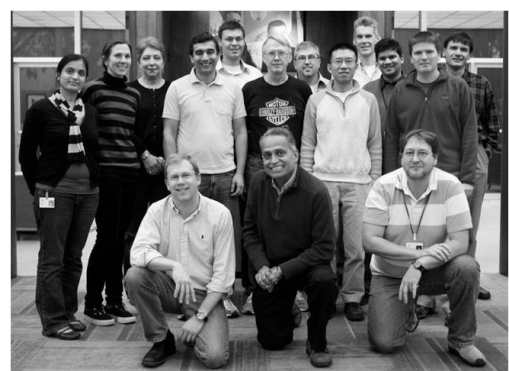

Figure 3: HP Labs Sustainable Ecosystems Research group, 2010.

rink for the entire hockey season. While very cost effective, the occasional warm air front would affect the quality of the ice and interrupt the hockey season. Today, arenas typically have refrigeration systems to improve the availability of the ice, albeit at a much higher cost than "natural" ice.

The Internet also depends on climate-controlled facilities, particularly for the data centers that house servers and networking equipment. Without the refrigeration systems, the IT infrastructure would overheat and the availability of the Internet could be interrupted. Some of the larger data centers, such as Google's data centers at The Dalles, Oregon, look a lot like hockey arenas.

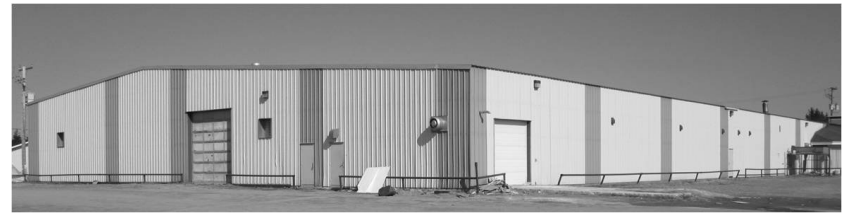

Figure 4: St. Walburg arena.

\section{Effective planning}

Achieving challenging objectives requires effective planning and execution. Perhaps the simplest, most effective plan I've ever seen was the Eagle's game plan for defeating the Meadow Lake Stampeders, one of our competitors in the "Big 4 Hockey League". Our plan had only two steps, which I'll state exactly as they were written by our coach on the chalkboard in our dressing room: 1) piss off Diesel. 2) score on the power play. (For Computer Scientists, the implied third step is "repeat".) Diesel was perhaps the Stampeders best defenseman. However, he had a very bad temper. We repeatedly found a way to aggravate him, and each time he would do something to be assessed a penalty.

Effective planning is also important for successful research. As an example, the team I am on at HP Labs is developing a "net-zero" energy data center. The plan for this data center 
involves three steps: 1) "avoid doing nothing"; i.e., trying to keep the infrastructure as busy as possible, to obtain the best return on investment; 2) "do nothing well"; i.e., minimize operational costs if no work is being done; and 3) "stick to the energy budget"; our renewable energy supply is very limited, so we need to use it carefully, and minimize how much we borrow from the grid as we need to quickly repay it to maintain our net-zero energy goal.

\section{Creativity}

A challenge for researchers and hockey players alike is coming up with novel solutions to problems. Note that a solution does not have to be sophisticated to be effective.

I was never the most creative player on the ice for the Eagles. However, there was one situation that I applied my creativity to achieve a desired solution. There is a cult classic movie about hockey called "Slapshot". Three central figures in this movie are the "Hanson brothers". All three have long mullets and wear black glasses with white tape around the nose piece, creating a distinctive look for these aggressive hockey players. What most people do not know is that the fourth Hanson brother played in the same league as the Eagles. Well, he wasn't an actual Hanson brother, but he looked and played like them. Before one game against his team, I went to a costume store and bought 20 pairs of black framed glasses, and put white tape around the nose piece of each. My plan was to have every player on the Eagles wear them on the ice for warm-up, to aggravate him and get him off his game. However, our coach thought that might not be the best idea, even though some of the guys looked a lot like the Hansons with the glasses on. Instead, he gave the glasses to some of our fans. They quickly made a few signs, all to focus "Hanson's" attention on them. Even his own team found this extremely funny. I'm not sure how he figured out I was the guy behind this, but on my first shift he came straight after me. He got ejected from the game, so I guess my plan worked.

Simple ideas can also be effective in Internet research. In the early 2000s, I attended a talk from a group in HP Labs who were working on improving the energy efficiency of data center cooling. I started thinking how would my dad (the original MacGyver) solve this? My proposal, based on the problem constraints I was aware of, was to have the doors on the backs of the racks of IT equipment tilt backwards, to reduce the mixing of hot and cold air in the data center. A member of the cooling group simulated this, and found that it lowered the data center temperatures by 4 degrees Celsius, a very significant reduction for such a simple solution.

\section{Disagreements with officiating}

In hockey, disagreements with the officiating are commonplace. Sometimes it is over a call that was made; in other cases, it is about a call that was not made. For example, in one game I was hit in the face by an opponent's stick (a penalty, even if accidental); the referee was only about 6 feet away when it happened, but did not call a penalty. Bleeding from my nose and chin, I loudly voiced my disagreement with his assessment, but to no avail.

Similarly, I expect every researcher reading this editorial has had disagreements with "officials" . In many cases, these are in response to comments or decisions made by anonymous reviewers on your conference or journal submissions. My personal record for a prolonged disagreement involved a patent application. After 7 rebuttals, 1 appeal, 4 different attorneys representing us and the departure from HP of three of the inventors, we resolved our differences and were granted a patent, nine years after the application was filed.

\section{Show up to win}

In 1991, the Eagles created themselves a place in hockey history by winning a best-of-five playoff series 0 games to 2. We were playing the North Battleford Barons in the first round of the playoffs. The first two games were very physical, and both were won by the Barons. However, the Barons refused to play the third game, back in St. Walburg. They told the league that we were too rough, and that the league should eject our entire team from the series and award it to them. Fortunately, the league did not agree with their logic, and refused. We won the series when the Barons forfeited, as shown by the newspaper headline in Figure 5.

A very similar event happened in my work with HP. My colleagues and I were involved in a project to resolve several performance issues with the Internet site of a large company. One night, my colleagues and I figured out the root cause of one of the problems. When we reported what we had found the next morning, a different group from another company involved in the project refuted our claims, stating they simply could not be the root cause of that particular problem. The customer eventually asked both groups to come to their data center and work through it together. To make a long story short, my colleague and I showed up, but the other group did not. When the meeting time came and went, the customer said "I guess we know what the problem is."

\section{Barons forfeit Big 4 series}

\author{
Figure 5: Battlefords News-Optimist article, Feb. 27, 1991.
}

\section{Social networking}

Sometimes it is not what you know, but who you know. People often overlook the fact that hockey is a great social networking tool. During my tenure with the Eagles, I played with farmers, truck drivers, oil rig workers, police officers, a lawyer, two morticians (both of whom were goalies!), an EMT, a scuba instructor, several former professional hockey players, and people with a wide variety of other skills.

Social networking is a very important aspect of life in the research community. Whether it is for assistance with a particular aspect of a research project, finding program committee members for a workshop or conference, or numerous other tasks that require expertise that someone else possesses, it is important to develop a social network.

\section{Quantifying performance}

Hockey leagues often keep very detailed records of various attributes of the game. With the Eagles, it was no exception. Some years, like 1990-91, we did very well, finishing in third place in the Big 4 League with a record of 17 wins and 9 losses. The 1995-96 team, after a 4 year hiatus from playing in the league, was a different story; one win in 24 games.

However, statistics do not always tell the whole story. In 1989-90, the Lloydminster Border Kings finished in first place, with a record of 29 wins and only 3 losses. That season the Eagles finished in sixth place, with 14 wins, 16 losses 
and 2 ties. Based on those statistics, the Vegas odds makers would have expected the Border Kings to easily defeat us in a best-of-five playoff series. However, regular season standings do not mean much in the playoffs. We devised and executed a plan that led us to a 3 games to 1 series win over the Border Kings. Figure 6 shows the headline from the Lloydminster newspaper following the series.

Performance evaluation is an essential tool in Internet research. It is difficult to demonstrate whether improvements have been made without it. At the same time, remember that statistics do not always tell the whole story.

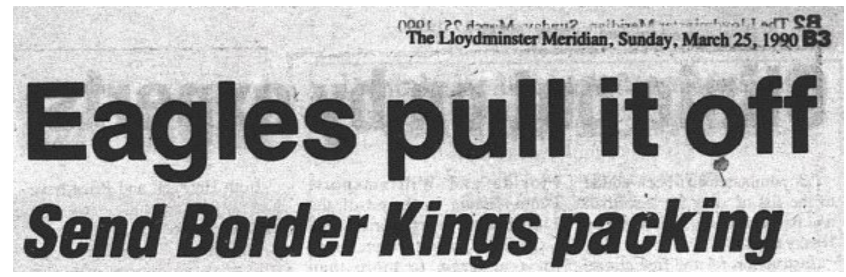

Figure 6: Lloydminster Meridian article, March 25, 1990.

\section{Anticipation}

There is a hockey phrase that is commonly used in business: skate where the puck is going, not where it's been. In other words, you need to anticipate what is going to happen, so that you can take advantage of it. The best example from hockey I can think of happened in an Eagles playoff game.

In the 1989-1990 season, the Big 4 hockey league used a round robin format for the first round playoff series. Two pools of three teams played off, with the top two teams from each pool advancing to the semi-finals. The round-robin games were played like regular season games; if tied after three periods, then a five minute sudden death overtime periods was played. If still tied, then each team received one point. Our final first round game was against the North Battleford Barons. They had to win the game to advance to round 2, we only needed a tie. After three periods, we were tied. In overtime, we took a penalty with only a few minutes left. The Barons really poured on the pressure. My teammates who were killing the penalty were unable to get the puck out of our zone, to alleviate the pressure and enable them to change. From my vantage point on the bench, it seemed like an eternity. Finally, one of our players got control of the puck and shot it down the ice. One of our penalty killers, Curt Pylypow (third from left, back row of Figure 2), suddenly skated as hard as he could down the ice. I was thinking to myself, he needs to change, he's exhausted! However, Curt had realized that the Barons had pulled their goalie for an extra attacker, and anticipated that when the Eagles iced the puck, the Barons power play unit would not only change for rested players on their bench, but that they would expect the Eagles to change their penalty killing unit as well. Anyway, Curt beat everyone down the ice, and scored a short-handed, empty-net, playoff-series winning goal in overtime - a very rare feat.

Anticipating how Internet technologies (or their use) might evolve is a skill possessed by successful researchers. Recognizing how things might unfold over time enables researchers to identify problems that may be artificially delaying a desired state from being reached. The earlier a researcher can anticipate these, the greater their potential reward.

\section{Having fun}

Most people who play hockey do so because it is a lot of fun. In some cases, the players also contribute to the enjoyment of others. For example, the Eagles goaltender in 1989-1990, Kevin Armstrong, would do a handstand after each victory, as shown in Figure 7, for the amusement of the fans.

Helping to build a better Internet can be a lot of fun too. As an example, in 2010 several colleagues invited me to coauthor a paper on powering a data center from farm-waste. Unlike solar or wind, farm waste can provide a $24 \times 7$ supply of renewable energy. The manure is converted to methane, and the methane can be burned to produce electricity. A data center needs lots of electricity to power the servers, but it also needs lots of cooling to keep the servers from overheating. Often, this comes from using more electricity; however, in the farm-waste design, the waste heat from the power generators would be used to produce chilled water, making the cooling process much more efficient. So, not only will the data center run on a renewable energy supply, but it would need less power than a typical data center.

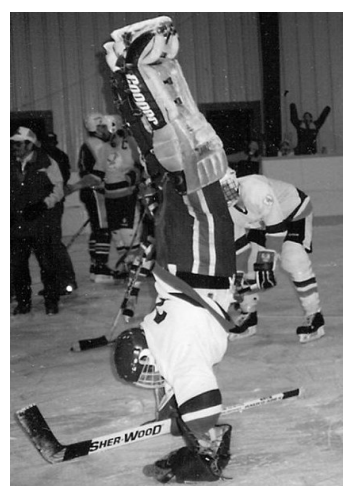

Figure 7: Victory celebration.

\section{Parting shots}

Unfortunately for me, my days of playing contact hockey are behind me. However, this season I am volunteering as an assistant coach for the Carstairs Redhawks, a team in one of the best amateur hockey leagues in Canada. Thus far into my coaching career, I've learned that it is a lot different than playing. It does seem to have numerous similarities to managing a research project though. However, elaborating on those will have to be the subject of a separate article.

\section{Acknowledgments}

The author would like to thank Michele Duczek of the Lloydminster Public Library, Alana Schweitzer of the Battlefords News-Optimist, Jeff Mogul of HP Labs, Niklas Carlsson of Linköping University, as well as HP Labs for taking a chance on a hockey player, and the St. Walburg Eagles for teaching me how to help build a better Internet.

\section{References}

[1] M. Arlitt, "The top ten similarities between playing hockey and building a better Internet (extended version)", HP Labs Technical Report HPL-2012-1, January 2012. 